\title{
Proposition of a Solution for the Setting of the Abrasive Waterjet Cutting Technology
}

\author{
J. Valíček ${ }^{1,2}$, M. Harničárová ${ }^{3,4}$, M. Kušnerová ${ }^{3,5}$, R. Grznárik ${ }^{4}$, J. Zavadil $^{5}$ \\ ${ }^{1}$ Institute of Geonics AS CR, Studentska 1768, 70800 Ostrava-Poruba, Czech Republic, jan.valicek@vsb.cz \\ ${ }^{2}$ Institute of Clean Technologies for Mining and Utilization of Raw Materials for Energy Use, VŠB - Technical University of \\ Ostrava, 17. listopadu 15/2172, 70833 Ostrava-Poruba, Czech Republic, jan.valicek@vsb.cz \\ ${ }^{3}$ Institute of Physics, Faculty of Mining and Geology, VŠB - Technical University of Ostrava, 17. listopadu 15/2172, \\ 70833 Ostrava-Poruba, Czech Republic, marta.harnicarova@vsb.cz \\ ${ }^{4}$ Nanotechnology Centre, VŠB - Technical University of Ostrava, 17. listopadu 15/2172, 70833 Ostrava-Poruba, \\ Czech Republic, marta.harnicarova@vsb.cz \\ ${ }^{5}$ RMTVC, Faculty of Metallurgy and Materials Engineering, VŠB - Technical University of Ostrava, 17. listopadu 15/2172, \\ 70833 Ostrava-Poruba, Czech Republic, jaromir.zavadil@vsb.cz
}

\begin{abstract}
The submitted paper aims to clarify the abrasive waterjet technology, particularly from the point of view of produced surface topography. It provides a new insight into the deformation process caused by the effect of abrasive waterjet and into the possibilities of using the surface topography for solving the issues of optimization of the process. The subject of study is a system of cutting tool, material and final surface topography and optimization of their parameters. The cutting or disintegrating tool of abrasive waterjet technology is flexible. The trajectory of its cut traces is strictly determined here by disintegration resistance at critical moments of tool-material interaction. The physico-mechanical character of the interaction within the cut will manifest itself in the final surface condition. This process can be re-analysed by measuring the selected elements of topography and roughness on the final surface, namely depending on the depth of the cut, technological parameters of the tool and mechanical parameters of the material. The mentioned principle is the basis of the presented solution. It lies in the analytical processing and description of correlation interrelations between set technological and measured topographical quantities in relation to the depth of cut and the type of material.
\end{abstract}

Key words: Abrasive waterjet cutting of materials, surface topography function, surface roughness, correlation relations, optimization of technology.

\section{INTRODUCTION}

$\mathrm{T}$ HE PRINCIPLE of liquid jet machining is based on the generation of high-pressure in a liquid (most frequently water), which in the course of flowing through a small cross-section tube acquires very high kinetic energy. Thus a flexible tool able to machine almost all engineering materials is created. The cutting process in the technology using an abrasive waterjet (AWJ) is the abrasive waterjet disintegration process. A material is subjected to the force, stress and deformation action of a cutting tool of AWJ type. The tool represents here a high-speed stream of a mixture of water and abrasive material. The aim of optimization of technological parameters of the process of cutting is to achieve optimal parameters of the cut in order to reach the required cutting depth, minimum roughness, and last but not least minimum economic cost. A mechanism of antagonism between external and internal reactive physical and mechanical factors induced by the cutting tool will achieve a balance that will be represented in the final form by a topography function of condition of cut wall surface generated in the plane of cut. As for the AWJ technology, what is meant is a cutting, or machining tool with mechanical properties somewhat different from those of classical cutting, machining and drilling tools in machine and other industries. This cutting tool is essentially not a rigid but a considerably flexible tool, and thus the trajectory of its cut trace changes quickly in critical moments of interaction with the material. The process of material cutting by the AWJ stream is in principle given by the elementary action of the liquid and abrasive particles. The essence of action of force follows from the impingement speed in contact with the surface of cutting front in the plane of contact angle. This is a case of interaction between the effective flow field of AWJ and the instantaneous geometric dimensions of surface interactive area of material in the plane of cut being subject to this AWJ flow field. The reverse reaction of material causes changes in the process of cutting, changes in original parameters of material and changes in initial factors of AWJ flow field. Material cutting utilizing the AWJ technology is characterised by a typical curvature and a retardation of trace of the cut behind the tube in the course of deepening the cut. The selection of unsuitable technological parameters of the tool not respecting actual strength and elasticity of the material causes intensive curvature, great roughness and not reaching the design depth.

\section{STATE OF THE ART IN ABRASIVE WATERJET CUTTING}

Around 1980, the abrasive waterjet technology was first commercialised as a new effective technology for processing various engineering materials. Since the introduction of this technology, a great deal of research and development has been conducted towards exploring its applications. When compared with thermal cutting technologies, abrasive waterjet cutting is very attractive investment wise for a number of applications. However, this 
technology also has disadvantages inherent in loud noise and surface quality. On the cut wall surfaces, surface irregularities in the form of striations, waviness and surface roughness are observed.

In the course of exertion of stress on the material being cut, on an interactive small area the abrasive waterjet cutting of structural components of material occurs, including the potential destruction of them in contact, due to the abrasive waterjet $[1,2,3]$. The impact of individual particles has an elastic-plastic character; if in the impact the plastic component predominates, an abrasive grain can cut and be fixed into the material both in the plane of cutting front and in the plane of cut walls. The cutting effect on the whole area of the cut is then the accumulation of effects of individual particles acting simultaneously in the effective quantity and at the effective speed of impingement. The size and the shape of chips depend on the number of simultaneously acting active edges and walls of abrasive particles and on the trajectory of their motion.

Characteristic factors are as follows:

- speed of a particle,

- mass flow rate,

- sharpness of wall angles,

- hardness of the material of a particle,

- size and shape of a particle,

- physical and mechanical properties of the material of a workpiece.

The physical and mechanical properties of the workpiece material determine the intensity of reaction forces and characterise or include each material into classes of cuttability of the material using an abrasive waterjet $[4,5]$. Up to now, generally an opinion has prevailed that the cutting process and the analytical solution for it are complicated from the physico-mechanical point of view, i.e. that the unambiguous physico-mathematical description of functions taking place in the process is complicated with regard to the complexity of the whole set of engineering, technology and material factors entering the process. The issue of the physico-mechanical principle of material disintegration and the generation of a new surface by abrasive waterjet cutting remains even at present unsolved and is thus open. The mechanism of AWJ cutting is primarily studied by analytical methods. The mechanism of material removal is still little explored. Many specialists who are concerned with this issue $[1,2,3]$ agree on the fact that in material disintegration the mechanisms of cutting, plastic deformation, fatigue and fracture participate. However, these mechanisms do not act separately, but they act in various combinations.

Therefore, determination of the optimal regime of AWJ ensures the effective and efficient usage of mechanical power for material cutting and influences the other important variables affecting the cutting, such as the costs of the whole technological process. In this paper, the depth of cut and the local deviation of the cut trace from the normal plane are considered to be performance measures as in many industrial applications it is the main constraint on process applicability [4]-[14]. The problem was approached by the authors in an original way. Based on the above-mentioned facts, in the presented contribution we describe a new approach to the problems concerned.

\section{EXPERIMENTS}

The material used in the experimental work is the AISI 309 steel with a thickness of $10 \mathrm{~mm}$. For experiments, a CNC cutting machine WJ2020B-1Z-D, (Fig.1.) from the PTV company was used. The experiment was carried out within the framework of an academic cooperation with the Institute of Geonics AS CR, v. v. i.

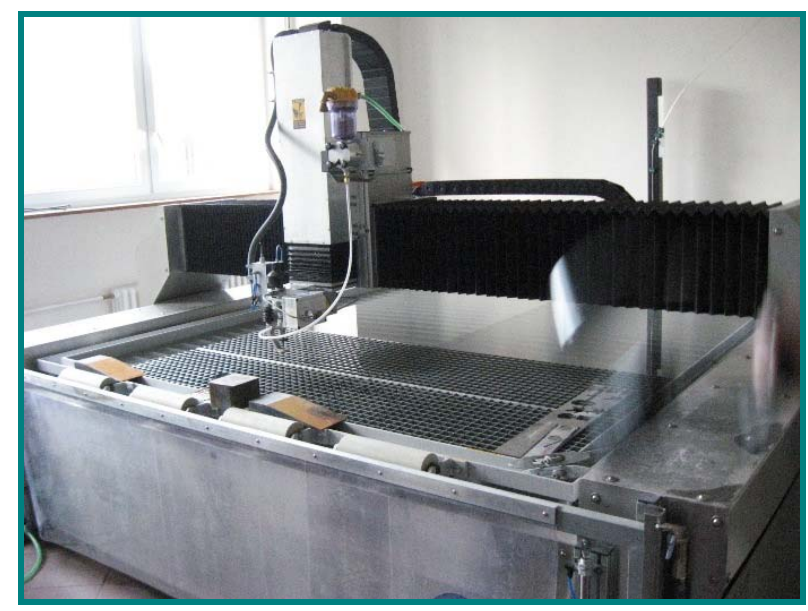

Fig.1. General view of the cutting machine CNC WJ2020B-1Z-D produced by PTV.

Experimental conditions are given in Tab.1. Altogether 60 experiments were carried out using the mentioned cutting machine and the mentioned material.

Table 1. Technology parameters of abrasive waterjet cutting system in the course of verification field operational test.

\begin{tabular}{|c|c|c|c|}
\hline $\begin{array}{c}\text { TECHNOLOGY } \\
\text { FACTORS }\end{array}$ & UNIT & SYMBOL & VALUE \\
\hline Liquid pressure & $\mathrm{MPa}$ & $\mathrm{p}$ & 300 \\
\hline $\begin{array}{c}\text { Water orifice } \\
\text { diameter }\end{array}$ & $\mathrm{mm}$ & $\mathrm{dv}_{\mathrm{o}}$ & 0.247 \\
\hline $\begin{array}{c}\text { Abrasive nozzle } \\
\text { diameter }\end{array}$ & $\mathrm{mm}$ & $\mathrm{d}_{\mathrm{abro}}$ & 0.752 \\
\hline $\begin{array}{c}\text { Abrasive nozzle } \\
\text { length }\end{array}$ & $\mathrm{mm}$ & $\mathrm{l}_{\mathrm{a}}$ & 76 \\
\hline $\begin{array}{c}\text { Abrasive mass } \\
\text { flow rate }\end{array}$ & $\mathrm{g} / \mathrm{min}$ & $\mathrm{m}_{\mathrm{a}}$ & 250 \\
\hline $\begin{array}{c}\text { Nozzle-surface } \\
\text { distance }\end{array}$ & $\mathrm{mm}$ & $\mathrm{L}$ & 2 \\
\hline Traverse speed & $\mathrm{mm} / \mathrm{min}$ & $\mathrm{v}_{\mathrm{p}}$ & 150 \\
\hline Abrasive size & $\mathrm{MESH}$ & - & 80 \\
\hline $\begin{array}{c}\text { Abrasive } \\
\text { material }\end{array}$ & - & - & $\begin{array}{c}\text { Barton } \\
\text { garnet }\end{array}$ \\
\hline
\end{tabular}

We measured the 3D topography of studied surfaces using an optical profilometer FRT MicroProf, manufactured by the company Fries Research \& Technology GmbH (FRT), Germany. On the basis of measurement (Fig.2.), data were analysed and interpreted to describe theoretically the topography of the surface [15]. 


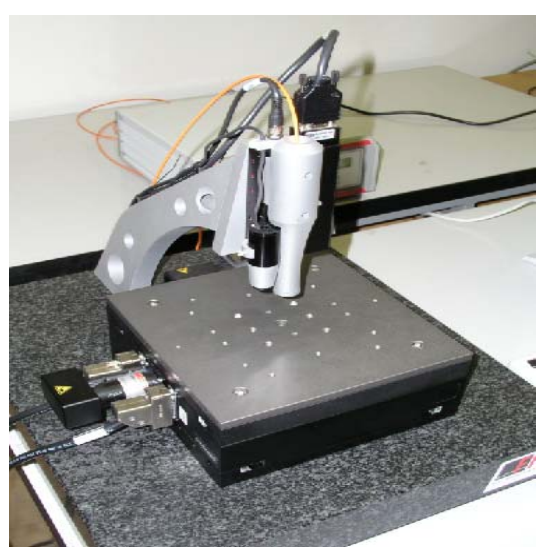

Fig.2. General view of the optical profilometer FRT MicroProf produced by FRT.

Using a CHR 150 optical sensor, the sample is illuminated by focused white light. The internal passive optics, using chromatic aberration, splits the white light into different colours.

A spectrometer detects the colour of the light reflected by the sample and determines the position of the focus point, and by means of an internal calibration table, the vertical position measured on the sample surface. The optical sensor is non-movable, the sample under study lies on a scanning table. The same optical fibre collects scattered light from the surface under study. This light is analysed by means of the spectrometer. Results of the measurement have the form of a vector and/or the matrix of heights of the surface irregularities. The basic parameters of FRT MicroProf are as follows: xy minimum range: $200 \times 200 \mu^{2}$, xy maximum range: $(100 \times 100) \cdot 10^{-6} \mu^{2}$, measurement range: $300 \mu \mathrm{m}$ $-3 \cdot 10^{3} \mu \mathrm{m}$, vertical resolution: $3 \cdot 10^{-3} \mu \mathrm{m}$, lateral resolution: $2 \mu \mathrm{m}$, maximum angle of inclination of the surface roughness to the mean plane: 30 .

\section{TOPOGRAPHY FUNCTION}

A model of topography function (3) with regard to specific and optimized technology factors of abrasive waterjet cutting technology has not been systematically and comprehensively studied and published yet. The knowledge of topography function is of high importance for further analyses and for the prediction of the condition of surface topography at a change in technology regime, a change in the material being cut and at the feedback control of final surface roughness.

Surface roughness always grows where deformation stress and deformation force diminish, it means where the working ability of the tool decreases. It has considerably high values at the beginning of cut in the so-called initiation zone (i.e. to the 1-2 mm depth of cut), where the rigidity of the tool is high, but cutting into the material is most energy consuming (8). The optimum choice of process technology factors based on theoretical assumptions is connected with the achievement of good quality and performance. The majority of theoretical works are orientated towards the presentation of laboratory measurements of the authors and/or the comparison of authors' own results with results of other laboratories but without deep analyses and generalization.
So that comparable results may be obtained, actually measured values are very often distorted by their idealization. Thus a so-called "trimming" of a special entry region at the beginning of cut, which is called the initiation zone, occurs. Just the shape and the geometric factors of initiation zone are of great diagnostic importance to the evaluation of technology projects.

By means of geometric phenomena of the created surface topography (Fig.3.), solving the practical problems the most engineers and users face in the AWJ technology process, maximizing the performance of AWJ production system, and determining the values of the process parameters that will reach the desired product quality are possible. The usage of surface topography functions for AWJ helps the subjects-operators in their work process; this help is evident mainly in the sphere of making decisions concerning the correct selection of technology regime, because their decisions are only based on their experience.

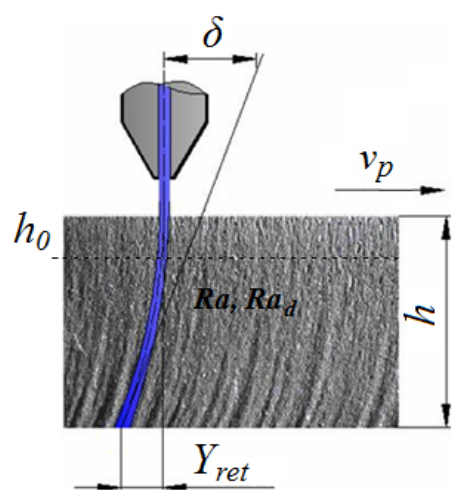

Fig.3. Visual interpretation of geometrical parameters of generated surface.

This is done to derive function (1)

$$
R a, R a_{d}=\mathrm{f}\left(h, E_{m a t}, v_{p}, m_{a}, Y_{r e t}\right)
$$

where $h$ is the depth of cut, $E_{\text {mat }}$ is Young's modulus, $v_{p}$ is the traverse speed, $p$ is the water pressure, $m_{a}$ is the abrasive mass flow rate and $Y_{\text {ret }}$ is the retardation of trace in neutral plane, $R a$ is roughness in the plane of cut trace and $R a_{d}$ is radial surface roughness. Thus two types of roughness are distinguished, namely roughness $R a$ directly in the trace and $R a_{d}$ in the plane of the cut (Fig.3.), where the roughness is measured in practice most frequently. In the abrasive waterjet cut, in addition to the increasing roughness $R a$, the following items are measures of a decrease in tool rigidity: retardation intensity $Y_{\text {ret }}[\mathrm{mm}]$ and deviation of trace $\delta\left[^{\circ}\right]$ of cut depending on instantaneous depth of cut $h[\mathrm{~mm}]$. These geometric parameters are also connected with the technological parameters, especially with the selection of traverse speed of cutting head and with the physicomechanical parameters of material. To assess the surface roughness as permanent deformation, merely two geometric conditions, namely initial and final states, are usually respected, and thus one should proceed in small elementary steps $d x$. This behaviour of surface irregularities is defined by relation (2). 


$$
R a=\frac{1}{l_{n}} \int_{0}^{l_{p}}|y(x)| d x
$$

The topography function $R a_{d}$ is given by (3):

$$
R a_{d}=R a_{j} \cdot\left(\sqrt{\left(\frac{v_{p}}{v_{\text {popt }}} \cdot \frac{m_{\text {aopt }}}{m_{a}} \cdot \frac{p_{\text {opt }}}{p} \cdot \frac{d_{f}}{d_{\text {fopt }}}\right)} \cdot e^{\ln \left(\sqrt{(\log h)^{2}}+\sqrt{\left(\log \frac{1}{Y_{\text {ret }}}\right)^{2}+R a_{\text {rad }}^{2}}\right)}\right)
$$

where: $R a_{j}$ is the unit surface roughness. The first member under radical is called a technological factor $K_{\text {tech. }}$. Parameter $d_{f}$ is a focusing tube diameter.

The coefficient of cuttability of the material using a flexible beam $K_{\text {cut }}$ is calculated according to the following relation

$$
K_{\text {cut }}=\frac{R a \cdot h}{Y_{\text {ret }}}=\frac{10^{12}}{E_{\text {mat }}^{2}}=\text { konst }
$$

The main topographic parameters $R a, Y_{\text {ret }}, \delta$ according to Fig.3. can be analytically expressed as in (5), (6), (7), (8), (9).

$$
\begin{gathered}
\delta=\operatorname{arctg}\left(\frac{Y_{r e t}}{h}\right) \\
\delta_{0}=\operatorname{arctg}\left(\frac{Y_{r e t 0}}{h_{0}}\right)
\end{gathered}
$$

where:

$$
Y_{\text {ret }}=\frac{R a \cdot h}{K_{\text {cut }}} ; Y_{\text {ret } 0}=\frac{R a_{0} \cdot h_{0}}{K_{\text {cut }}}
$$

An important analytical factor is the determination of geometric parameters and position of equilibrium/neutral plane $h_{0}$ in the cut produced by abrasive waterjet cutting $[4,10]$. The depth level of the plane $h_{0}=K_{\text {cut }} / R a_{0}$ is illustrated in Fig.3. It forms the marked boundary of a relatively smooth cut above the level $h_{o}$. Below the level $h_{o}$, the curvature of trace and roughness grow vigorously. The explanation of this phenomenon can be seen in the equalization of tensile and compressive stresses in the cut. The value $h_{o}$ varies for different materials and is a function of $K_{\text {cut }}$ and $E_{\text {mat }}$. However, statistically determined values of trace roughness $R a_{0}=3.7 \mu \mathrm{m}$ are constant in the plane $h_{0}$ and do not depend on the type of material. Generally, it is a case of the depth level in cuts, where tensile stresses and compressive stresses will be equalized. Roughness $R a$ in the cut trace can be determined according to (8):

$$
R a=\frac{Y_{\text {ret }} \cdot K_{\text {cut }}}{h} ; R a_{0}=\frac{Y_{\text {ret } 0} \cdot K_{\text {cut }}}{h_{0}}
$$

or also according to (9)

$$
R a=-10 \cdot\left(\frac{1-K_{c u t}}{K_{c u t}-h}\right)
$$

The main topographic parameters $R a, Y_{\text {ret }}, \delta$ are, according to the above-mentioned equations, in functional relation to Young's modulus $E_{\text {mat }}$. The calculation of optimal parameters (Tab.2.) is thus executed according to the equations derived by us (after their conversion of the derived physical equations that were in the form of algorithm presented in the patent application [16] to regression relations) according to Young's modulus $E_{\text {mat }}$ [MPa] [9]. The optimized technological parameters are then obtained by calculation for a specific depth level of neutral plane $h_{0}$ in the given material. At the level of neutral plane, a stress-strain balance exists in the cut. Variables $h_{0}, Y_{\text {ret }}$ and $R a_{d 0}$ are put into (3) and a sought optimized parameter is calculated. In the given equation, this parameter is contained in the first member under radical.

Optimized diameter of tube (10):

$$
d_{\text {aopt }}=0.223+7.458 \cdot 10^{-6} \cdot E_{\text {mat }}-2.016 \cdot 10^{-11} \cdot E_{\text {mat }}^{2}+3.167 \cdot 10^{-17} \cdot E_{\text {mat }}^{3}
$$

Optimized ratio - focusing tube / water orifice diameter ratio (11):

$$
K_{\text {dadv }}=0.067+1.850 \cdot 10^{-6} \cdot E_{\text {mat }}-5.190 \cdot E_{\text {mat }}^{2}+8.125 \cdot 10^{-18} \cdot E_{\text {mat }}^{3}
$$

Optimized water orifice diameter (12):

$$
d_{\text {vopt }}=d_{\text {aopt }} \cdot K_{\text {dadv }}
$$

Optimized cutting head speed (13):

$$
v_{\text {popt }}=422,438-0.004 \cdot E_{\text {mat }}+1.961 \cdot 10^{-8} \cdot E_{\text {mat }}^{2}-3.640 \cdot 10^{-14} \cdot E_{\text {mat }}^{3}
$$

Optimized abrasive mass flow rate (14):

$$
m_{\text {aopt }}=74.139+0.002 \cdot E_{\text {mat }}-6.688 \cdot 10^{-9} \cdot E_{\text {mat }}^{2}+1.048 \cdot 10^{-14} \cdot E_{\text {mat }}^{3}
$$

Optimized pump pressure (15):

$$
p_{\text {opt }}=42.0344+0.001 \cdot E_{\text {mat }}-3.411 \cdot 10^{-9} \cdot E_{\text {mat }}^{2}+5.403 \cdot 10^{-15} \cdot E_{\text {mat }}^{3}
$$

For the calculation of depth of initiation zone, the following relation (16) holds true:

$$
h_{i z}=h_{j} 0.5\left(\frac{v_{\text {popt }}}{v_{p}} \cdot \frac{m_{a}}{m_{\text {aopt }}} \cdot \frac{p}{p_{\text {opt }}} \cdot \frac{d_{\text {fopt }}}{d_{f}}\right)^{0.25} 10^{\log \left(\log \left(\frac{0.1 R a_{o} K c u t}{0.1 R o+1}\right) \cdot\left(\frac{R a_{d_{0}}}{R a_{o}}\right)^{0.5}\right)}
$$

where $K_{\text {cut }}$ is the coefficient of cuttability using an abrasive waterjet, $R a_{0}$ is trace roughness in neutral plane $h_{0}, R_{a d 0}$ is radial roughness in neutral plane $h_{0}$. For AISI 309 , $E_{\text {mat }}=200 \mathrm{GPa}$; at $K_{\text {tech }}=1$. 
Table 2. Technologically optimized values.

\begin{tabular}{|c|c|c|}
\hline Parameter & Value & Unit \\
\hline$d_{\text {aopt }}$ & 1.161 & $\mathrm{~mm}$ \\
\hline$K_{\text {dadv }}$ & 0.294 & - \\
\hline$d_{\text {vopt }}$ & 0.342 & $\mathrm{~mm}$ \\
\hline$v_{\text {popt }}$ & 135.508 & $\mathrm{~mm} \cdot \mathrm{min}^{-1}$ \\
\hline$m_{\text {aopt }}$ & 386.515 & $\mathrm{~g} \cdot \mathrm{min}^{-1}$ \\
\hline$p_{\text {opt }}$ & 188.823 & $\mathrm{MPa}$ \\
\hline
\end{tabular}

\section{RESULTS AND DISCUSSION}

Of the technology of abrasive waterjet cutting of materials, the creation of relatively great roughness in the so-called initiation zone, i.e. in the area of entry of the abrasive waterjet to the material, is characteristic. According to the type of material and the selection of technological parameters of the tool, the achieved depth ranges from 0.5 to $2.5 \mathrm{~mm}$. The prediction of final roughness and initiation zone in the case of topography functions under different technological conditions is shown in Fig.4. In this figure, the influence of technology factors on the depth of initiation zone in the given material is evident. The core of the solution consists of the distribution functions of measured values of proposed basic geometric parameters of surface and the study of regular relations among them in relation to the mechanical parameters of the material and in relation to the parameters of the cutting tool. This statement can be well illustrated on evolution of the curves in Fig.4., namely for material steel AISI 309 with modulus of elasticity in tension of $200 \mathrm{GPa}$. We see here theoretical predictive values of radial roughness $R a_{d}$ calculated in accordance with (3) represented by smooth curves. It is apparent that they fit very well the oscillating values from the records of the profilometer. Optimal feed rate $v_{p o p t}=v_{p A}=136 \mathrm{~mm} / \mathrm{min}$ was calculated for the given material according to (13) and Table 2., which summarises also other optimised parameters according to the relevant equations. By changing an optimal feed rate, for example, to the values $v_{p B}=34 \mathrm{~mm} / \mathrm{min}$, or $v_{p C}$ $=542 \mathrm{~mm} / \mathrm{min}$ we obtain according to (17) technological factors $K_{\text {techA }}=1, K_{\text {techB }}=0.5$, or $K_{\text {tech } C}=2$. In results we get then also adequate values $R a_{d A}, R a_{d B}, R a_{d C}$, and analogically for the depth and roughnesses in the initiation zone we get parameters $h_{i z A}, h_{i z B}, h_{i z C}$. The roughnesses on the first contact with the tool can be read on the adequate curves $h_{i z}$. Average value of the measured roughness of the dividing cut in the case of $R a_{d A}$ is $12.3 \mu \mathrm{m}$, in the case of $R a_{d B}$ it is $10.2 \mu \mathrm{m}$, and in the case of $R a_{d C}$ it is $22.2 \mu \mathrm{m}$. Roughnesses at the depth levels $h_{i z}, h_{0}$, or $h_{\text {lim }}$ can be read from the diagram. In regard to the output and economic parameters and quality parameters we were able to make the following conclusions: The curve $R a_{d A}\left(K_{\text {tech }}=1\right)$ gives good roughness with good economics and output. The curve $R a_{d B}\left(K_{\text {tech }}=2\right)$ gives very good roughness, but the output rapidly drops due to low feed rate and the price of output rapidly increases. The curve $R a_{d C}\left(K_{\text {tech }}=0.5\right)$ shows very high output due to high feed rate and cheap operation, but also excessively high roughness of the cutting wall. Impact of the change of technology is here simulated in a simplified manner by change of the feed rate, with preservation of all other parameters according to Table 2. It is, however, possible to mutually combine the change of technological parameters contained in (17) and model mathematically the final state of the cut according to the presented procedure. This can be easily realised, for example, in the program Matlab.

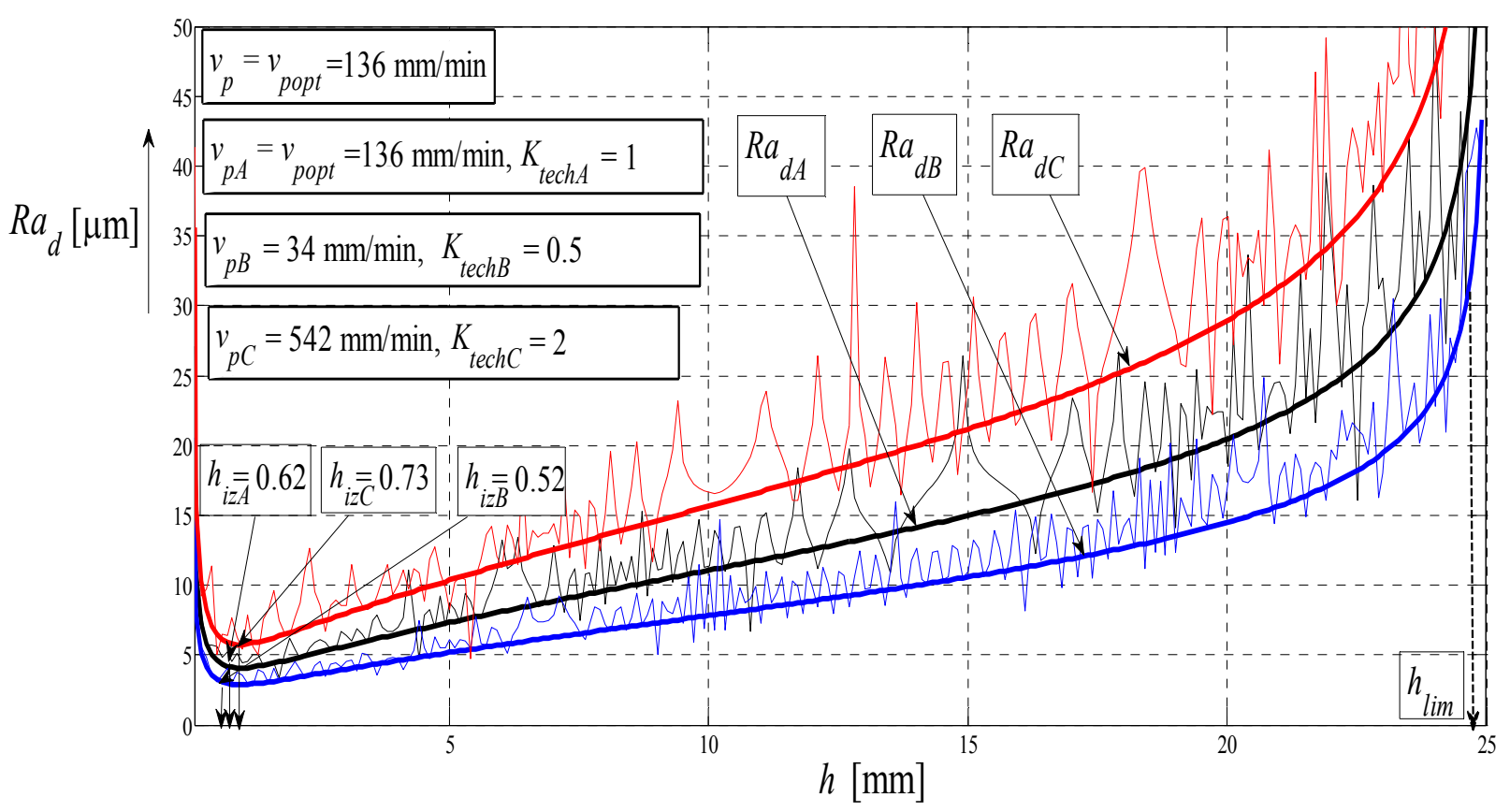

Fig.4. Prediction of maximal depth of initial zone for AISI 309, $E_{\text {mat }}=200 \mathrm{GPa}$ and $v_{p}=v_{\text {popt }}=136 \mathrm{~mm} . \mathrm{min}^{-1}$. 
To achieve the economically effective process with the least energy losses, it is necessary to determine correctly the technological parameters of the process. As optimization technologies for various kinds of materials are given by relation criteria, the cutting speed, focusing tube diameter, abrasive mass flow rate and optimized pump pressure were selected $[9,10]$. The technology factor for the selection of (17):

$$
K_{\text {tech }}=\sqrt{\left(\frac{v_{p}}{v_{\text {popt }}} \cdot \frac{m_{\text {aopt }}}{m_{a}} \cdot \frac{p_{\text {opt }}}{p} \cdot \frac{d_{f}}{d_{\text {fopt }}}\right)}
$$

This technology factor determines the influence of selected technological parameters on surface topography in various kinds of materials. Simultaneously, it also expresses money and energy consumption [7]. In Fig.5. optimized technology factors for material cutting are stated.

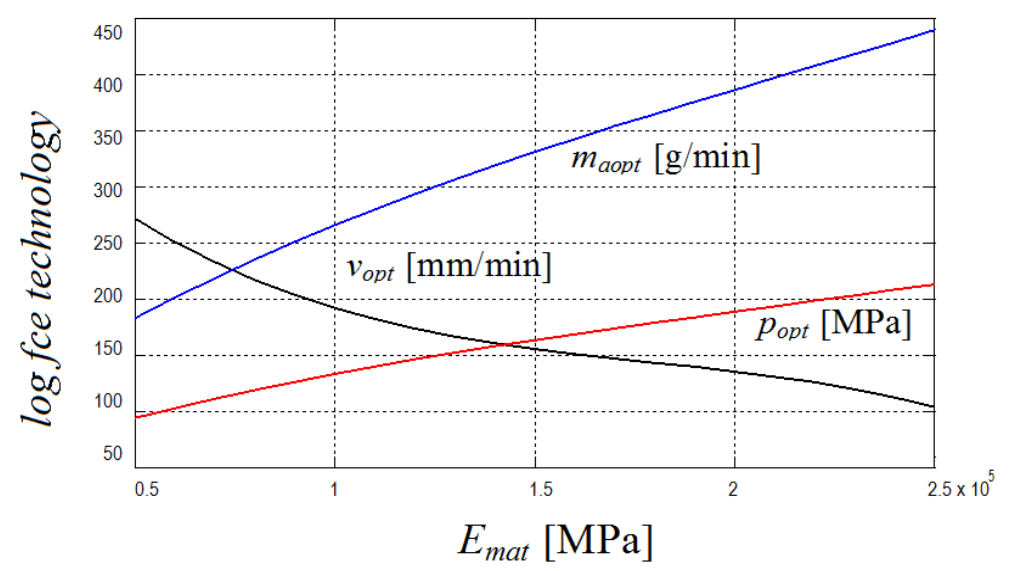

Fig.5a. Optimized technological parameters according to $E_{m a t}[\mathrm{MPa}]$ according to the above-presented (13), (14) and (15).

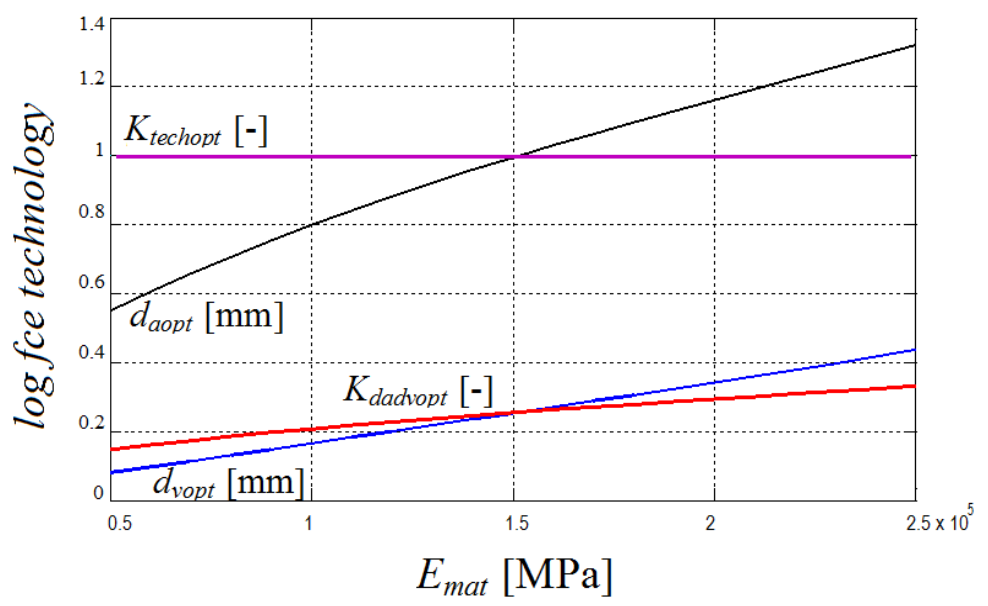

Fig.5b. Optimized technological parameters according to $E_{\text {mat }}[\mathrm{MPa}]$ according to the above-presented (10), (11), (12) and (17).

\section{CONCLUSION}

The aim of the submitted contribution was to show the possibilities of using the topography of surface in the optimization of technological parameters. The analysis of the problem, proposal of the solution, and the interpretation of geometric parameters of surface topography were made. From the surface a topography function, forming the basis for predicting the quality and control of abrasive water jet technology for material cutting, is derived in an original way. The basic form of an equation for the predictive calculation of roughness as well as other equations for various application purposes, especially for the calculation of optimal traverse speed, optimized focusing tube diameter, optimized mass flow rate, optimized pump pressure, and technologically important parameter $K_{\text {tech }}$ for the comparison of money and energy consumption in selected technology regimes are presented here. The derived relations are generally valid for different types of materials according to their Young's moduli and also according to required depths of cut. Optimized technological parameters are then obtained by calculation for a specific depth level of neutral plane $h_{0}$ in the given material. At the level of neutral plane, a stress-strain balance exists in the cut. New findings supplement the theoretical basis of abrasive waterjet technology for material cutting and provide an assumption of suitable application in practice. 


\section{ACKNOWLEDGEMENT}

The contribution was prepared in the framework of the project Institute of Clean Technologies for Mining and Utilization of Raw Materials for Energy Use, Reg. No. CZ.1.05/2.1.00/03.0082 supported by the Research and Development for Innovations Operational Programme financed by the EU Structural Funds and from the state budget of the Czech Republic and the project of AS CR No. AV0Z30860518. The authors would like to thank also to the IT4Innovations Centre of Excellence project Reg. No. CZ.1.05/1.1.00/02.0070 and RMTVC project No. CZ.1.05/2.1.00/01.0040.

\section{REFERENCES}

[1] Hashish, M. (1989). A model for abrasive - waterjet (AWJ) machining. Journal of Engineering Materials and Technology, 111 (2), 154-162.

[2] Hashish, M. (1988). Visualization of the abrasive waterjet (AWJ) machining. Experimental Mechanics, 28 (2), 159-169.

[3] Hashish, M. (1984). A modeling study of metal cutting with abrasive water jets. Journal of Engineering Materials and Technology, 106 (1), 88-100.

[4] Hloch, S., Valíček, J., Samardžic, I., Kozak, D., Kušnerová, M. (2012). Classification of technical materials according to classes machinability for hydroabrasive cutting. Metalurgija, 51 (1), 125-128.

[5] Kovacevic, R. (1992). Monitoring the depth of abrasive waterjet penetration. International Journal of Machine Tools \& Manufacture, 32 (5), 725-736.

[6] Momber, A., Kovacevic, R. (1998). Principles of Abrasive Water Jet Machining (1st ed.). Springer.

[7] Kolahan, F., Khajavi, A.H. (2011). Modeling and optimization of abrasive waterjet parameters using regression analysis. International Journal of Aerospace and Mechanical Engineering, 5 (4), 248253.

[8] Tozan, H. (2011). Fuzzy AHP based decision support system for technology selection in abrasive water jet cutting processes. Tehnički Vjesnik-Technical Gazette, 18 (2), 187-191.
[9] Hloch, S., Valíček, J. (2011). Prediction of distribution relationship of titanium surface topography created by abrasive waterjet. International Journal of Surface Science and Engineering, 5 (2-3), 152-168.

[10] Hloch, S., Valíček, J., Simkulet, V. (2009). Estimation of the smooth zone maximal depth at surfaces created by Abrasive Waterjet. International Journal of Surface Science and Engineering, 3 (4), 347-359.

[11] Valíček, J., Držík, M., Hryniewicz, T., Harničárová, M., Rokosz, K., Kušnerová, M., Barčová, K., Bražina, D. (2012). Non-contact method for surface roughness measurement after machining. Measurement Science Review, 12 (5), 184-188.

[12] Karpinski, A., Louis, H., Peter, D., Scheer, C., Sudmersen, U., Monno, M., Ravasio, C. (2004). Effect of pressure fluctuations and vibration phenomenon on striation formation in AWJ cutting. In Proceeding of the 17th International Conference on Water Jetting, 79 September 2004. Mainz, Germany: BHR Group Limited, Cranfield, 123-136.

[13] Henning, A., Anders, S. (1998). Cutting-edge quality improvements through geometrical modelling. In BHR Group Conference Series Publication : International Conference on Jetting Technology, 2123 September 1998. Brugge, Belgium: Professional Engineering Publishing LTD, 321-328.

[14] Zeng, J., Kim, T.J. (1992). Developement of abrasive waterjet kerf cutting model for brittle materials. In Lichtarowicz, A. (ed.) Jet Cutting Technology. Springer, 483-501.

[15] Kušnerová, M., Valíček, J., Hryniewicz, T., Palková, Z., Václavík, V., Řepka, M., Bendová, M. (2013). A proposal for simplifying the method of evaluation of uncertainties in measurement results. Measurement Science Review, 13 (1), 1-6.

[16] Valíček, J., Borovička, A., Hloch, S., Hlaváček, P. (2012). Design method for the technology of hydroabrasive cutting of materials. Patent application number: US 2012/0022839 A1. Washington, D.C.: U.S. Patent and Trademark Office.

Received February 13, 2013. Accepted October 25, 2013. 